\title{
American thriller novel as an effective means of scientific communication
}

\author{
Mikhail Pokotylo ${ }^{1^{*}}$ \\ ${ }^{1}$ Rostov State Transport University, 2, Rostovskogo Strelkovogo Polka Narodnogo Opolcheniya Sq., \\ Rostov-on-Don, 344038, Russia
}

\begin{abstract}
In the modern world, the problem of the perception of science in society is relevant, and it is impossible to expect scientific breakthroughs and the introduction of new technologies into everyday life without its solution. Anti-scientology views have taken root in society with the active assistance of the media. In this regard, it seems useful to analyse the features of the science image formation by means of fiction. The purpose of the article is to study the possibilities of using the genre of the American thriller novel as a means of scientific communication that can inspire society's confidence in science. To achieve the stated purpose, the analysis of the peculiarities of the science perception in modern society is carried out; the methods of communication between scientists and society are considered, and the specific features of the thriller genre are revealed. The author came to the conclusion that the genre nature of the thriller novel makes it possible to tell mass audience about new technologies in a fascinating way, take a fresh look at scientific achievements, comprehend the moral principles of science, and build trust in innovative technologies in modern society.
\end{abstract}

\section{Introduction}

In the conditions of a modern information society, the problem of the perception of science and technology by society deserves special attention, because further development of scientific research and introduction of scientific developments into everyday life depends on its solution.

The fact that antiscientific views have spread in the modern world is of particular concern in the scientific community, because it calls into question the need for scientific research, and criticizes the scientist' activities. In this regard, there is a need to develop new strategies and tactics of professional communication that can influence the attitude of society towards science and technology.

Society's perception of scientists and science has not always been unambiguous. Professor Harry Collins and lecturer Robert Evans distinguish three waves of science perception by society in the second half of the 20-th century [1].

These ways are summed up in Table1:

\footnotetext{
* Corresponding author: pokotylo2014@yandex.ru
} 
Table 1. Three waves of science perception by society by Professor Harry Collins and lecturer Robert Evans.

\begin{tabular}{|c|c|c|}
\hline $\begin{array}{c}\text { Waves of science } \\
\text { perception }\end{array}$ & Time period & Characteristic features of a period \\
\hline The first wave & $1950-1960 \mathrm{~s}$ & flourishing of scientism \\
\hline The second wave & $1970-1980 \mathrm{~s}$ & $\begin{array}{c}\text { strengthening of antiscientific sentiments } \\
\text { in society }\end{array}$ \\
\hline The third wave & $1990 \mathrm{~s}-$ to present & $\begin{array}{c}\text { decline in the authority of science and the } \\
\text { crisis of scientific expertise }\end{array}$ \\
\hline
\end{tabular}

1) The first wave is associated with the flourishing of scientism, when science was perceived in society as a powerful force capable of solving, if not all, then many of the problems of humankind. The authority of the scientist and science during this period was indisputable. The influence of scientists on the socio-political processes in many countries was so great that, "although they were not in power, we can talk about the Parliament of science" [2].

2) The second wave is associated with strengthening of antiscientific sentiments in society. People started understanding that scientific advances also have a downside. As Toss Gascoigne, Bernard Schiele et al. note, during this period "Hiroshima cast a long shadow on science" [2]. The transition to the second wave of science perception in society is associated with the emergence of a number of philosophical works in which it was proved that the "scientific truth" is not absolute", and "what is presented as a scientific fact is actually only a complex compromise between different groups within the scientific environment" [3].

3) The third wave is associated with the decline in the authority of science and the crisis of scientific expertise. Trust in science and scientists in society has declined.

Fluctuations in the perception of science by society (from its deification to the loss of confidence in it) are caused, first of all, by those socio-political and cultural processes that took place in the world in the second half of the 20-th century. Within the industrial society, scientists were engaged in the production of knowledge. In the 1980s in the West, the information society begins to take shape, and scientists are losing their monopoly on scientific knowledge within it, since during this period various social groups are involved in the process of production and exchange of knowledge. The advent of the Internet and its spreading has accelerated this process.

A characteristic feature of the information society is strengthening of the role and influence of the media in almost all spheres of activity, including science. Even in the 19-th century, the media began to assume the role of an intermediary between scientists and the public in connection with the growth of professionalization and specialization of science. Taking into account the fact that in the scientific environment of the 20 -th century, it was widely believed that "popularization of science is an unworthy occupation for a real scientist", the responsibility of delivering scientific information to the public finally passed to the media, which affected the attitude of society towards science. In the studies of American and British scientists [4], attention is drawn to the fact that the media do not always pay enough attention to scientific news, admit inaccuracies in the presentation of information, overdramatize events and strive for sensationalism. In turn, the journalists draw attention to the fact that not all scientists are ready and willing to interact with the public [4]. In the 1990s, the situation starts changing dramatically. The scientists and, first of all, representatives of the humanities begin reconsidering their attitude to interacting with a mass audience focusing on the mass media in order to preserve the autonomous status of science in society, increase their authority, as well as financial support for scientific research. The emergence of electronic media has created a demand for "hipster science", 
within which the border between scientific and unscientific knowledge is blurred, while "the media component is sometimes more important than scientific" [5].

Such changes have led to the formation of the phenomenon of "popular science", which determines the attitude of society to the activities of scientists. Practice shows that scientific knowledge that leaves the academic community is transformed in a society of nonspecialists [5]. In a mass audience there is a demand for scientific knowledge and education in the form of entertainment, therefore in modern society "science is becoming both a form of entertainment and an element of contemporary art" [6].

The new branch of knowledge, i.e. scientific communication, is called upon to combine the theory and practice of promoting science in society. It can return the legitimacy of scientific knowledge, and support the authority of science in society. At the moment, scientific communication is aimed at finding effective means that can, on the one hand, draw attention to science and technology, and, on the other, build public confidence in it.

The works of mass culture can be regarded as such means. The scientists and science become the object of the image in these works. Modern mass culture has become an integral part of "popular science", from which various strata of society learn scientific information, and prospects for the development of new technologies. Studies how to form the image of scientists in works of mass culture show that these images are often "exaggerated" and have "little in common with real scientific researchers". Moreover, the mass audience is forming "a sharply opposite opinion about the modern scientist: from frivolous and comedic to frightening and potentially dangerous" [7].

The study of mass culture as a means of scientific communication is associated with a change in the models of interaction between scientists and society. The attitude of society towards science is influenced not by the knowledge transmitted to the mass audience, but by the meanings that science carries. People comprehend science taking into account previously acquired knowledge, accumulated experience and beliefs. Fiction has an impact on people's beliefs, highlighting the cultural significance of science [8]. We live in an epoch of information technology, when there is a public demand for scientific information and education in the form of entertainment. Modern society perceives only that kind of information that is characterized by entertainment, emotionality, focussing on personalities, and supposes interactivity [9]. Such a request forces us to change the forms of providing scientific information, to attract new means to solve the problems of science popularization. In the UK and the USA, to popularize science, the power of the film industry is actively used, which make it possible to synthesize scientific and entertainment cultures [10].

Fiction and drama are the most adequate means of forming the image of science in society, since science appears to the reader or viewer not in the form of ready-made knowledge, but as a complex social process of collision between various values and interests [11]. According to the British researcher K. Shefferd-Barr, drama is "an ideal medium for the discovery of science to society," because the basis of drama is a conflict, and "science is a socially conflict area" [12]. In fiction, the image of science is formed with the help of the images of scientists who may or may not realize their social ambitions within the framework of the narrative. By focusing on the knowledge production process, fiction provokes readers' interest in scientific research, stimulates the development of technology, and can contribute to scientific discussions.

From our point of view, the thriller is an effective genre of mass culture that is capable of performing the functions of scientific communication. This genre has formed in the United States and found its expression both in fiction and cinema. 


\section{Materials and methods}

The purpose of this article is to study the possibilities of using the genre of the American thriller novel as a means of scientific communication that can form a positive image of science and innovative technologies in society.

To realize this purpose, it is necessary to solve the following objectives:

- to determine the genre nature and genre features of the thriller novel,

- to analyse the compositional structure and content of the cycle of thriller novels by the popular American writer James Rollins "Sigma Force" as a means of scientific communication.

To implement the above purpose and objectives, in accordance with the characteristics of the scientific research, the following methods were chosen:

- the method of literary hermeneutics, aimed at identifying the features of the reader's perception and interpretation of the images of science and innovative technologies presented in thriller novels;

- a sociological method that perceives works of art about scientists as a reflection of social trends and historical conditions for the development of society in a given period.

\section{Results}

For fiction of the 20-th century, the contamination of genres is characteristic. The result of this process was the emergence of new and transformation of already known literary genres. One of the new genres that emerged as a result of contamination and has become widespread in modern popular culture is the thriller novel. The thriller mixes elements of a number of other genres - detective, adventure, science fiction, romance, action. Therefore, it is not always possible to clearly define the boundaries of this genre. Elements of these genres are reflected in the thriller as well as thriller elements can be used in any genre of contemporary fiction. However, in many literary works the thriller genre is considered as a kind of detective story [13]. At the same time, the model of constructing a detective is rethought in a thriller. The task of the thriller character is not to solve a committed crime, but to destroy the enemy's plans [14].

The thriller's plot revolves around a series of events that evoke feelings of intense excitement or fear in the reader. The chronotope plays a special role in the plot of the thriller. As the plot develops, references to the future are given, which, on the one hand, create reader's tense expectation of future events, and on the other hand, do not allow him/her to accurately predict them [13].

Depending on the subject matter, there are different types of thrillers: religious, mystical, legal, psychological, spy, eco-thrillers, research thrillers, techno-thrillers [15]. The images of scientists and scientific research can be the focus of almost all types of the thriller, at the same time, the issues of scientific achievements and innovative technologies are often raised in the techno-thriller and thriller-adventure.

Scientific achievements and the role of new technologies in the modern world are vividly and excitingly described in the series "Sigma Force" by the popular American writer James Paul Tchaikovsky, who publishes his works under the pseudonym James Rollins. The writer began to work on this series in 2004, since then he annually pleases his fans with a new novel. At the moment, the Sigma Force series consists of 16 thriller novels. Each novel included in the series has its own plot and can be considered as an independent work of fiction, however, in addition to the subject matter, the compositional structure is common to all novels. Almost all thriller novels of the series have scientific and historical information, as well as notes in which the writer tells the readers which events are true and 
which are fiction. The writer often uses statements of various political and public figures as epigraphs to novels.

James Tchaikovsky has education of a veterinarian, he has many years of experience in a veterinary clinic, and therefore in his works various animals are described in detail and realistically, with terminology from the field of biology and medicine. The writer's passion for diving and speleology is also reflected in his work - the action in his novels takes place not only on the ground and in the air, but also underground (in caves) and under water. A distinctive feature of James Rollins' novels is the skilful use of graphic means that complement the literary text - diagrams, geographical maps and drawings allow the reader to imagine the place of action of the heroes, to immerse deeper into the fiction world.

Moving in time between the past and the present, the aspiration of the plot of James Rollins' novels to the future, the inability to predict the further course of events, arouse the reader's feeling of anxious expectation, and attract attention to the events. An intricate and interesting plot, in which reality and fiction are intertwined, do not let the reader get bored.

When creating his novels, the writer takes some historical event shrouded in mystery, as a basis, supplements it with his own version, often replacing real facts with fictional ones in the interests of the plot. For example, the source of the plot of the novel "The Crown of the Demon" was a historical fact - the establishment of the largest research and educational centre in the United States in the 19-th century - the Smithsonian Institution funded by the English chemist James Smithson, who bequeathed his inheritance to the American state to create an institution for the accumulation and dissemination of knowledge. Conventionally, the plot of the novel "Demon's Crown" can be divided into 3 parts. The first part describes the horror that people experienced when they met an unknown and dangerous phenomenon - attack wasps. These wasps were created in a special research laboratory with the financial support of the Japanese millionaire who decided to enslave the whole world with the help of these insects. In the second part, the main characters of the novel try to understand and solve the mystery of the ancient wasps. This part synthesizes the elements of a detective story and an adventure novel. The characters go on a journey to gain new knowledge and test the proposed hypotheses. The plot of the 3rd part is more like an action movie in which positive characters win. Almost all the novels included in the series are based on such a plot scheme (horror - finding out the reasons that caused the horror - the struggle between the protagonist and the antagonist). The harmonious combination of truth and fiction, the imagery of the narrative, allows an ordinary person, far from science, to perceive medical and biological terminology without much difficulty.

The main characters of the series are employees of the fictional special unit of the American army - the Sigma detachment; they are engaged in scientific research for the safety of not only the United States, but the whole world. All members of the detachment are former special forces officers, physically strong and resilient, able to use all types of weapons and military equipment in their activities. At the same time, they all underwent retraining in several scientific areas and are familiar with all the achievements of modern science and technology. By the nature of their work, Sigma employees interact with scientists who do not work for the US military forces and are often foreign nationals. The series presents a number of images of civil scientists who are engaged in research in the field of medicine, genetic engineering, archaeology, history, zoology, veterinary medicine. James Rollins' novels take place in genetic laboratories, design offices, medical centres, nature reserves, museums and libraries.

Quite often "civilian" scientists consciously and unconsciously act on the side of a secret organization - "Guild". The mystery with which the "Guild" is spoken of creates an atmosphere of fear. In essence, the series is built around the confrontation between negative characters (adherents of the "Guild") and positive characters (employees of the Sigma detachment and civil scientists who support them). At the same time, the task of the Sigma 
detachment is not only to investigate the dangerous crimes of the Guild, but to destroy the enemy's plans, saving the lives of many people. For the Guild, science and technology are means of enslaving the world and imposing their will. For the Sigma, science and technical innovations are the means to secure the world and make it comfortable for living.

The geographical location of the headquarters of the Sigma special forces is quite interesting. Sigma's office is located in the historic centre of the US capital, Washington D.C., under the building of the Smithsonian Institution. Thus, the writer emphasizes the role and influence of science on society in the modern United States, its proximity to government bodies and cultural institutions.

\section{Discussion}

In Western culture, works of fiction and art have long been used as a means of scientific communication. As Professor Martin Willis notes, modern mass fiction is increasingly influencing both university programs and future research [16]. Scientific achievements and technical innovations have become the object of depiction in theatrical performances as early as the 19-th century and continue to remain in the spotlight till the present time, influencing the formation of the perception of the scientists' activities in society [17].

The thriller genre is a part of mainstream literature that aims to entertain the readers. It is this genre by means of which it is possible to draw public attention to science and technology in the era of infotainment. The modern general reader, far from the scientific sphere, is not ready to perceive a voluminous black-and-white text using a large number of terms. The widespread use of entertainment content in scientific popularization can be the proof of it. Vivid images, musical accompaniment, colourful presentations, the purpose of which is to evoke the necessary associations and retain attention, are used for scientific enlightenment of the mass audience [6].

At the same time, the thriller genre can perform not only an entertainment function, but also solve an important task of shaping the image of science and trust in it. In the thriller genre, a combination of two forms of thinking - artistic and formal-logical - finds expression. Creative and scientific thinking are similar in their scenario. The detective model of the development of the thriller plot resembles the methodology of the scientists' work: first, facts are given, then on their basis hypotheses are put forward. Obtaining the new facts forces us to put forward a new hypothesis. Finally, the hypothesis is tested. With the help of the system of artistic images, the reader actively assimilates scientific information, at the same time, the detective plot develops reader's dialectical thinking [13].

In James Rollins' Sigma series of thriller novels, science is presented as a social process. In the centre of the image of the novels there is a team of scientists who serve in the Sigma detachment. Detachment "Sigma" is fighting the elusive members of the "Guild" who seek to subjugate the whole world. The writer shows the contradictory nature of scientific and technological progress with the help of the confrontation between "Sigma" and "Guild": on the one hand, science ensures the safety and comfortable living conditions for people, and on the other hand, science can become dangerous for society in the hands of fanatics with great ambitions. Mixing truth and fiction in his novels, the writer raises questions that are of concern to modern society how to use scientific achievements in everyday life, makes us think about what modern science is. Undoubtedly, the thriller genre is a work of fiction, not a popular science text. The main function of thriller novels is entertainment, but James Rollins uses the genre form of thriller not only for the entertainment of the reader, but also for his/her enlightenment and intellectual development, which is confirmed by the compositional structure of his cycle. 


\section{Conclusion}

In the history of human development, the attitude towards science has always been ambivalent. On the one hand, people admired scientific achievements, hoped for improving the quality of their life and solving urgent problems, on the other hand, they feared negative consequences from the implementation of scientific developments and the use of innovative technologies in everyday life. Scientists have always been interested in public support for scientific research, without which scientific and technological progress is impossible. Scientists have lost their monopoly on the production of scientific knowledge in information society, the process of reducing the prestige of science and scientists in society has begun. In the modern world, the mass media are beginning to influence practically all social institutions, including the scientific sphere, modifying it.

In the modern world, scientific knowledge goes beyond the professional community of scientists, which allows us to speak of the presence of "popular science", which has a significant impact on the perception of science and technology by society. On the part of society, there is a demand for scientific information and education in an entertaining form, which forces scientists to look for new forms of providing scientific knowledge to the mass audience of non-specialists and to use new means of communication.

In our opinion, the model of involving society in science can be implemented using popular genres of fiction. One of the popular genres of mass culture is the thriller genre, which is realized both in fiction and in cinema. The genre nature of the thriller, based on the reconsidering of the detective story and the use of elements of other genres (science fiction, adventure, action), makes it possible to use such works of art as an effective means of scientific communication.

The series of thriller novels by James Rollins "Sigma Force" raises issues that concern the modern society: the problems of the relationship between science and religion, the use of new technologies in the modern world, political and economic games, the mysteries of antiquity. The American writer builds the plot of his works on the basis of real historical facts, which are supplemented by his own interpretation. The harmonious combination of real facts and fiction, the active use of graphic means as a supplement to the literary text allows the reader to fully immerse in the depicted artistic world. However, the purpose of the works of James Rollins is not only the entertainment of the reader, but also the introduction to scientific knowledge and innovative technologies. This becomes evident thanks to the compositional structure of his novels, which includes historical and scientific references, as well as the obligatory section of the author's notes, in which the writer tells where the truth is in his text and where the lies begin and end.

The study and analysis of the images of a scientist in different historical epochs among different peoples allows us to trace the history of science development and reveal the change in the views of society on the values of scientific knowledge. Such knowledge will make it possible to identify patterns in the formation of the image of science for solving an applied problem - increasing the authority of science and strengthening the society trust in it. After all, public consciousness, like the consciousness of power and business structures, is formed not with the help of ideas and concepts, but with the help of images and perceptions. Knowledge of the laws governing the creation of a positive image of science will allow more active use of mass fiction to influence public consciousness.

\section{References}

1. H. Collins, R. Evans, Why Democracies Need Science (Polity, Cambridge, UK; Malden, Massachusetts, 2017)

2. T. Gascoigne, B. Schiele, J. Leach, et al., Communicating Science: A Global 
Perspective (Acton ACT 2601, Australia, ANU Press The Australian National University, 2020), DOI: http://doi.org/10.22459/CS.2020.

3. A. Borisova, Public relations in state departments [Svyazi s obschestvennost'yu v gosudarstvennykh strukturakh], 4, 82-93 (2019), [In Russ.]

4. Z. Vakhrameeva, Sign: problem area of media-education [Znak: problemnoye pole mediobrazovaniya], 3(29), 154-167 (2018), [In Russ.]

5. R. Abramov, A. Kozhanov, Sociology of science and technologies [Sotsiologiya nauki i tekhnologiy], 6(2), 45-59 (2015), [In Russ.]

6. R. Abramov, Cultivator [Kul'tivator], 5, 110-119 (2012), [In Russ.]

7. R. Iskanderova, Social and economic management: theory and practice [Sotsial'noekonomicheskoye upravleniye: teoriya i praltika], 1, 71-73, (2018), [In Russ.]

8. D. Kirby, Science and engineering in cinema [Nauka i tekcnika $v$ kino] (Alpina nonfiction, Moscow, 2018) (In Russ.)

9. N. Emel'yanova, Philosophy of Science and Technology, 23, 1, 128-140 (2018)

10. A. Hepburn, The Cambridge History of the English Novel, 693-708 (2012), DOI: doi.10.1017/09780521194952.045

11. M. Pokotylo, Filological aspect [Filologicheskiy aspect], 12(44), 158-170 (2018), [In Russ.]

12. K. Shepherd-Barr, Staging Science, 105-123 (2016), DOI: doi.10.1057/978-1-13749994-3_6.

13. O. Trembitskiy, T. Osadchaya, Filological aspect [Fililogicheskiy aspect], 10, 89-97 (2020), [In Russ.]

14. T. Shoshina, Search [Poisk], 1(10), 132-137 (2019), [In Russ.]

15. T. D’yakova, Lingua Mobilis, 3, 32-36 (2013)

16. M. Willis, Literature and Science, 208 (2014).

17. M.Willis, Scientific Performance on Street, Stage and Screen, 140 (2016), DOI: doi.10.1057/978-1-137-49994-3 